\title{
ANALISIS TINGKAT KEBISINGAN DI UNIVERSITAS SEMARANG DENGAN PETA KONTUR MENGGUNAKAN SOFTWARE GOLDEN 14
}

\author{
${ }^{1)}$ Fahrudin Ahmad, 2) Iryan Dwi Handayani, 3). Agus Margiantono \\ 1,2,3. Fakultas Teknik, Universitas Semarang, Jl. Soekarno Hatta Semarang \\ Email: fahrudinahmadfis@gmail.com
}

\begin{abstract}
Abstrak - Kampus Universitas merupakan suatu tempat dimana berlangsungnya proses belajar mengajar. Salah satu fakto runtuk mencapai kondisi lingkungan belajar yang baik adalah terhindar dari masalah kebisingan. Objek pada penelitian ini adalah kampus Universitas Semarang yang yang berlokasi di Jl.Arteri Soekarno-hatta dan terletak di tepi Jalan tol kaligawe- gayamsari. Kedua jalan tersebut merupakan jalur transportasi yang sangat ramai di kotaSemarang. Kawasan lingkungan kampus memerlukan lingkungan yang tenang dan tidak bising. Wilayah perkotaan sulit untuk mendapatkan lokasi kampus yang tenang. Penelitian ini mencoba mengungkapkan bagaimana evaluasi pada factor kebisingan yang terjadi selama proses belajar mengajar. Penelitian dilakukan di Universitas Semarang. Metode penelitian yang digunakan adalah metode deskriptif analitik. Penelitian ini dilakukan dengan cara mengukur tingkat kebisingan menggunakan Sound Level Meter (KRISBOW) tipe KW08-291 dengan mengambil beberapa titik pengambilan data yang tersebar di Universitas Semarang, baik lingkungan terbuka maupun tertutup. Dari hasil pengukuran kebisingan yang akan dilakukan berupa pemetaan kebisingan agar diketahui peta sebaran kebisingan di area kampus Universitas semarang. Nilai ambang batas tingkat kebisingan di lingkungan kampus rata-rata masih diatas $55 \mathrm{~dB}$. Hal ini menunjukkan bahwa tingkat kebisingan di lingkungan kampus Universitas Semarang belum sesuai dengan standar baku yang telah ditetapkan yaitu masih lebih besar dari (40 - 50 dBA) sesuai dengan KepMenLH No.48 Tahun 1996.

Kata Kunci : kebisingan, sound level meter, Nilai ambang batas kebisingan, keputusan Menteri negara lingkungan hidup no. 48 tahun 1996
\end{abstract}

\begin{abstract}
Campus is a place which is teaching and learning process occur. One factor that support a good learning environment is to avoid noise problems. The object of the research is the campus of Semarang University located on Jalan Arteri Soekarno-Hatta, it is located on the edge of the Kaligawe-Gayamsari toll road. Both roads includes the most crowded transportation routes in Semarang City.Campus area requires a quiet and silent environment. It is difficult for the urban areas to get a quiet campus environment. The study tries to reveal the evaluation on how the noise factors that occur during teaching and learning process. The study was conducted at Semarang University. The research method used is descriptive analytic method. The research was conducted by measuring the noise level using Sound Level Meter (KRISBOW) type KW08-291, several data collection points was taken at Semarang University, both open and closed environments around campus. The results of noise measurements would be carried out in noise mapping to know the noise distribution map in the campus area. The noise level in the campus is still above $55 \mathrm{~dB}$ on average. It shows that the noise level in the environment of Semarang University has not been in line with the predetermined standard that is still greater than (40 - $50 \mathrm{dBA})$ in accordance to the decree of the State Minister of the Environment number 48 of 1996.

Keywords: noise, sound level meter, noise threshold value, decree of the State Minister of the Environment number 48 of 1996
\end{abstract}

\section{PENDAhuluan}

Salah satu sarana yang terpenting dalam kegiatan belajar mengajar di kampus adalah tercapainya suasana kelas yang nyaman dan kondusif. Kampus merupakan suatu tempat dimana berlangsungnya proses belajar mengajar (Justian, Alex. 2012)

Proses belajar mengajar ini akan berlangsung dengan baik apabila berada pada lokasi lingkungan fisik yang baik yaitu kondisi yang memungkinkan para mahasiswa belajar dengan optimal, sehat, aman dan selamat. Salah satu faktor untuk mencapai kondisi tersebut yaitu terhindar dari masalah kebisingan (Feidihal. 2007).

Semakin tinggi pengguna jasa transportasi di wilayah perkotaan menyebabkan keramaian lalu lintas pada wilayah tersebut semakin meningkat. Tingginya intensitas kendaraan yang melintas di jalan raya kota tentunya mempunyai dampak yang besar terhadap lingkungan di sepanjang jalan yang dilewati kendaraan. Kendaraan-kendaraan tersebut dalam pengoperasiannya menimbulkan suara-suara seperti, suara mesin kendaraan yang keluar dari knalpot, suara klakson kendaraan maupun suara-suara yang diakibatkan oleh aktivitas dari mesin kendaraan yang lainnya. Pada level tertentu suarasuara tersebut masih dapat ditoleransi oleh pendengaran kita, dalam artian suara yang diakibatkan masih tidak menimbulkan suatu gangguan kenyamanan dan gangguan lainnya terhadap pendengaran kita, akan tetapi pada tingkat yang lebih tinggi suara yang ditimbulkan oleh kendaraan-kendaraan transportasi tersebut sudah dapat dikatakan sebagai suatu gangguan yang disebut polusi suara atau kebisingan (Djalante, S. 2010).

Jalur transportasi adalah sumber kebisingan di lingkungan kampus. Kebisingan yang diperbolehkan dalam kampus adalah 55 dB menurut Keputusan Menteri Negara Lingkungan Hidup No. 48 Tahun 1996 sehingga kampus-kampus yang berada di dekat jalan raya maupun jalan tol harus memenuhi standar tersebut. Lokasi kampus yang berada di dekat jalur transportasi ramai mengakibatkan adanya kebisingan saat kegiatan belajar mengajar berlangsung.

Besarnya mobilitas masyarakat yang semakin meningkat maka menyebabkan keramaian kota Semarang yang memberikan dampak bising dari ruas-ruas jalan kota Semarang. Sehingga perlu dilakukan penelitian pada kawasan kampus yang letaknya berada di samping jalan arteri di kota Semarang. Dilihat dari dampak kebisingan terhadap mahasiswa dapat terganggu konsentrasi saat membaca maupun berkonsentrasi, ketika kebisingan terjadi saat proses belajar mengajar 
berlangsung. Namun, kebisingan dalam kelas dapat di cegah dengan mengatur mahasiswanya sendiri. Sedangkan di luar kelas memerlukan solusi penanganan sendiri agar kebisingan tidak terpapar masuk ke dalam kelas dan mengganggu proses belajar mengajar.

Banyaknya kendaraan yang melintas di jalan tol maupun jalan arteri Soekarno-Hatta menyebabkan tingginya kebisingan di sekitar kampus Universitas semarang. Kebisingan ini di timbulkan karena letak Universitas semarang berada diantara jalan tol kaligawe-gayamsari dan jalan Arteri Soekarno-Hatta . Adanya dua jalan tersebut dilintasi kendaraan-kendaraan berat seperti truk dan lain-lain yang suara mesinnya menimbulkan kebisingan.

Berdasarkan uraian diatas, maka cara mengatasi masalah kebisingan dilingkungan kampus Universitas Semarang yang terletak di antara jalan yang sangat ramai yang setiap harinya dilalui banyak kendaraan harus dengan menggunakan metode yang tepat sasaran dan efektif. Untuk menganalisis tingkat kebisingan dan ketergangguan terhadap bising di kampus di kota Semarang khususnya kampus Universitas Semarang, maka penulis bermaksud untuk melakukan penelitian yang berjudul " Analisis Tingkat Kebisingan Di Universitas Semarang Dengan Peta Kontur Menggunakan Software Golden Surfer 14".

\section{TINJAUAN PUSTAKA}

Suara merupakan gangguan fisik dalam suatu medium (seperti gas, cairan atau padatan) yang dapat dideteksi oleh telinga manusia. Medium perambatan suara harus mempunyai massa dan bersifat elastis, sehingga gelombang suara tidak dapat merambat melalui ruang hampa. Respon telinga manusia terhadap tekanan suara memiliki jangkauan antara 2 x 10-5 Pa sampai $200 \mathrm{~Pa}$. Suara dengan frekuensi rendah dan tinggi kurang efektif diterima oleh telinga manusia dibanding dengan frekuensi medium (antara $500 \mathrm{~Hz}$ ) dan frekuensi tinggi (lebih dari $8000 \mathrm{~Hz}$ ) (Sasongko, Hadiyarto, 2000).

Kebisingan adalah bunyi yang tidak dikehendaki karena tidak sesuai dengan konteks ruang dan waktu sehingga dapat menimbulkan gangguan terhadap kenyamanan dan kesehatan manusia (Sasongko dan Hadiyarto, 2000). Kebisingan sering dan paling mudah didefinisikan sebagai suara yang tidak dikehendaki.

Untuk mengukur kebisingan di lingkungan kerja dapat dilakukan dengan menggunakan alat Sound Level Meter. Ada tiga cara atau metode pengukuran akibat kebisingan di lokasi kerja

\section{Pengukuran dengan titik sampling}

Pengukuran ini dilakukan bila kebisingan diduga melebihi ambang batas hanya pada satu atau beberapa lokasi saja. Pengukuran ini juga dapat dilakukan untuk mengevalusai kebisingan yang disebabkan oleh suatu peralatan sederhana, misalnya Kompresor/generator. Jarak pengukuran dari sumber harus dicantumkan, misal 3 meter dari ketinggian 1 meter.

\section{Pengukuran dengan peta kontur}

Pengukuran dengan membuat peta kontur sangat bermanfaat dalam mengukur kebisingan, karena peta tersebut dapat menentukan gambar tentang kondisi kebisingan dalam cakupan area.
Kode pewarnaan untuk menggambarkan keadaan kebisingan, warna hijau untuk kebisingan dengan intensitas dibawah 85 dBA warna orange untuk tingkat kebisingan yang tinggi diatas $90 \mathrm{dBA}$, warna kuning untuk kebisingan dengan intensitas antara $85-90 \mathrm{dBA}$.

3. Pengukuran dengan Grid

Untuk mengukur dengan Grid adalah dengan membuat contoh data kebisingan pada lokasi yang di inginkan. Titik-titik sampling harus dibuat dengan jarak interval yang sama diseluruh lokasi.

Nilai Ambang Batas untuk kebisingan di tempat kerja adalah intensitas tertinggi dan merupakan rata-rata yang masih dapat diterima tenaga kerja tanpa mengakibatkan hilangnya daya dengar yang tetap untuk waktu terus-menerus tidak lebih dari dari 8 jam sehari atau 40 jam seminggunya. Waktu maksimum bekerja adalah sebagai berikut.

Tabel 1. Nilai Ambang Batas Kebisingan

\begin{tabular}{|l|l|l|}
\hline No. & $\begin{array}{l}\text { TINGKAT } \\
\text { KEBISINGAN }(\text { dB })\end{array}$ & $\begin{array}{l}\text { PEMAPARAN } \\
\text { HARIAN }\end{array}$ \\
\hline 1. & 85 & 8 jam \\
\hline 2. & 88 & 4 jam \\
\hline 3. & 91 & 2 jam \\
\hline 4. & 94 & 1 jam \\
\hline 5. & 97 & 30 menit \\
\hline 6. & 100 & 15 menit \\
\hline
\end{tabular}

\section{Sumber kebisingan}

Kebisingan disebabkan adanya sumber bunyi yang bergetar. Getaran sumber suara mengganggu molekul-molekul udara di sekitar sehingga molekul-molekul ikut bergetar. Getaran sumber ini menyebabkan terjadinya gelombang rambatan energi mekanis dalam medium udara menurut pola rambatan longitudinal (Sasongko dan Hadiyarto, 2000)

Sumber bising ada dua bentuk yaitu :

1. Sumber titik, berasal dari sumber suara yang berhenti. Penyebaran sumber bising ini berbentuk bola-bola konsentris dengan sumber bising sebagai pusat dan menyebar dengan kecepatan suara 360 meter/detik.

2. Sumber garis, berasal dari sumber bising yang bergerak dan menyebar di udara dalam bentuk silinder konsentris dengan kecepatan 360 meter/detik. berbentuk silinder yang memanjang. Sumber bising ini berasal dari kegiatan transportasi.

Pada sumber titik, kebisingan dapat diprediksi dengan menggunakan model matematis dengan persamaan sebagai berikut :

$$
\mathbf{L} 2=\mathrm{L} 1-20 \log (\mathbf{r} 2 / \mathbf{r} 1) \mathrm{dBA}
$$

dengan :

L2= tingkat kebisingan pada jarak r2 dari sumber

$$
\text { L1= tingkat kebisingan pada jarak r1 dari sumber }
$$
$(\mathrm{dBA})$

Sumber utama kebisingan lingkungan berasal dari kebisingan tempat kerja, kebisingan jalan raya dan kebisingan dari aktivitas rumah tangga. 


\section{Pengertian Peta Kontur}

Menurut Rahmat Kusnadi (2018) Peta kontur adalah peta kontur adalah peta yang menggambarkan sebagian bentukbentuk permukaan bumi yang bersifat alami dengan menggunakan garis-garis kontur. Kontur ini dapat memberikan informasi relief, baik secara relatif, maupun secara absolute. Informasi relief secara relatif ini, diperlihatkan dengan menggambarkan garis-garis kontur secara rapat untuk daerah terjal, sedangkan untuk daerah yang landai dapat di perlihatkan dengan menggambarkan garis-garis tersebut secara renggang.

Aplikasi lebih lanjut dari garis kontur adalah untuk memberikan informasi slope (kemiringan tanah rata-rata), irisan profil memanjang atau melintang permukaan tanah terhadap jalur proyek (bangunan) dan perhitungan galian serta timbunan (cut and fill) permukaan tanah asli terhadap ketinggian vertikal garis atau bangunan. Garis kontur dapat dibentuk dengan membuat proyeksi tegak garis-garis perpotongan bidang mendatar dengan permukaan bumi ke bidang mendatar peta. Karena peta umumnya dibuat dengan skala tertentu, maka untuk garis kontur ini juga akan mengalami pengecilan sesuai skala peta.

\section{Pengertian Surfer}

Surfer adalah salah satu perangkat lunak yang digunakan untuk pembuatan peta kontur dan pemodelan tiga dimensi yang berdasarkan pada grid. Perangkat lunak ini melakukan plotting data tabular XYZ tak beraturan menjadi lembar titik-titik segi empat (grid) yang beraturan. Grid adalah serangkaian garis vertikal dan horisontal yang dalam Surfer berbentuk segi empat dan digunakan sebagai dasar pembentuk kontur dan surface tiga dimensi. Garis vertikal dan horisontal ini memiliki titik-titik perpotongan. Pada titik perpotongan ini disimpan nilai $\mathrm{Z}$ yang berupa titik ketinggian atau kedalaman. Gridding merupakan proses pembentukan rangkaian nilai $Z$ yang teratur dari sebuah data XYZ. Hasil dari proses gridding ini adalah file grid yang tersimpan pada file .grd ( Mandala Adi, 2012).

\section{METODE PENELITIAN}

Metode penelitian yang digunakan adalah metode deskriptif analitik, yaitu menguraikan fakta-fakta kebisingan yang terjadi di lingkungan universitas semarang dengan mengukur tingkat kebisingan yang dilakukan oleh penyebab utamanya, kemudian dilanjutkan dengan membandingkan dengan standar baku kebisingan yang diijinkan sesuai keputusan menteri negara lingkungan hidup nomor : Kep-48/ MENLH/ 11/ 1996.

\section{Diagram Alir Penelitian}

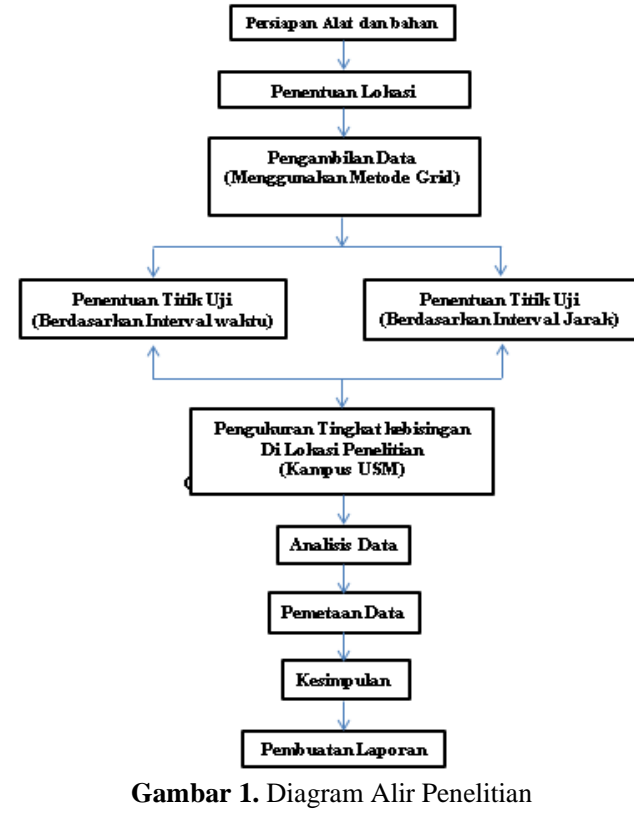

Cara Kerja Pengambilan Data

Berikut adalah cara kerja mengukur kebisingan di Lingkungan kampus USM yaitu :

1. Metode Pengukuran Kebisingan

Metode pengukuran intensitas sebaran kebisingan di lingkungan kampus USM disesuaikan standarisasi sesuai dengan Keputusan Menteri Negara Lingkungan Hidup Nomor:Kep-48/ MENLH/ 11/ 1996 tentang Nilai ambang batas Kebisingan dengan waktu pengukuran siang dan malam. Pengukuran pada siang hari selang waktu pukul $06.00-22.00$ dan aktivitas malam hari selama 8 jam (LM) pada selang 22.00 - 06.00, dengan demikian 2 waktu pengukuran pada siang hari dan pada malam hari 2 waktu pengukuran.

2. Metode Pengolahan dan Analisis Data

Data hasil pengukuran kebisingan dibuat model pemetaan dengan menggunakan sofware Golden Surfer 14 dan untuk memperjelas gambaran kebisingan pada lokasi pengambilan sampel, maka peta hasil pengolahan software golden surfer 14 di tempatkan pada peta dari google earth dengan sebelumnya menentukan titik maksimum dan minimun garis lintang maupun garis bujur peta yang akan ditampilkan.

\section{IV.HASIL DAN PEMBAHASAN \\ Pengukuran Kebisingan di lingkungan kampus Universitas Semarang}

Salah satu sumber kebisingan yang terjadi pada proses pembelajaran di USM adalah kebisingan yang diakibatkan dari aktivitas di luar ruang kuliah yaitu aktivitas kendaraan bermotor, genset, maupun aktivitas pekerja proyek bangunan. Aktivitas pemotongan keramik dan pengeboran beton ini sangat dikeluhkan oleh mahasiswa dan dosen, jika dilakukan pada waktu proses belajar mengajar dilakukan. Pengukuran kebisingan dilakukan dengan menggunakan alat Sound Level Meter. Pengukuran kebisingan dilakukan dengan menentukan titik pengukuran kemudian pengukuran 
dilakukan pada waktu yang berbeda dan dalam keadaan yang berbeda.

Tabel 2. Data Hasil Penelitian

\begin{tabular}{|r|r|r|r|r|r|r|r|r|r|}
\hline Titik & \multicolumn{1}{|c|}{$\mathrm{X}$} & \multicolumn{1}{|c|}{$\mathrm{Y}$} & $\begin{array}{c}\text { Hari } \\
\text { Biasa } \\
\end{array}$ & $\begin{array}{c}\text { Hari } \\
\text { Biaga } \\
\text { Malam }\end{array}$ & $\begin{array}{c}\text { Hari } \\
\text { Libur } \\
\text { Pagi }\end{array}$ & $\begin{array}{c}\text { Hari } \\
\text { Libur } \\
\text { Malam }\end{array}$ & $\begin{array}{l}\text { Lebaran } \\
\text { Malam }\end{array}$ & $\begin{array}{c}\text { Lebaran } \\
\text { Pagi }\end{array}$ & $\begin{array}{l}\text { Mutuk } \\
\text { Baku }\end{array}$ \\
\hline 1 & 378 & 213.38 & 92 & 87 & 89 & 86 & 91 & 95 & 85 \\
\hline 2 & 367.5 & 207.46 & 91 & 85 & 88 & 85 & 88 & 91 & 85 \\
\hline 3 & 357 & 201.54 & 85 & 85 & 86 & 82 & 83 & 86 & 85 \\
\hline 4 & 346.5 & 195.62 & 87 & 85 & 84 & 86 & 83 & 87 & 85 \\
\hline 5 & 336 & 189.7 & 84 & 85 & 82 & 85 & 80 & 84 & 85 \\
\hline 6 & 325.5 & 183.78 & 84 & 84 & 78 & 83 & 84 & 84 & 85 \\
\hline 7 & 315 & 177.86 & 87 & 78 & 81 & 79 & 72 & 90.2 & 85 \\
\hline 8 & 304.5 & 171.94 & 76 & 78 & 76 & 85 & 72 & 83.1 & 85 \\
\hline 9 & 294 & 166.02 & 76 & 72 & 76 & 60 & 71 & 76 & 85 \\
\hline 10 & 283.5 & 160.1 & 74 & 74 & 74 & 57 & 72 & 82 & 85 \\
\hline 11 & 273 & 154.18 & 72 & 75 & 72 & 58 & 70 & 72 & 85 \\
\hline 12 & 262.5 & 148.26 & 76 & 74 & 76 & 74 & 72 & 76.4 & 85 \\
\hline 13 & 252 & 142.34 & 87 & 86 & 87 & 74 & 84 & 87 & 85 \\
\hline 14 & 241.5 & 136.42 & 85 & 83 & 85 & 77 & 82 & 87 & 85 \\
\hline 15 & 231 & 130.5 & 85 & 78 & 85 & 76 & 84 & 85 & 85 \\
\hline 16 & 220.5 & 124.58 & 85 & 78 & 85 & 74 & 85 & 85.6 & 85 \\
\hline 17 & 210 & 118.66 & 85 & 72 & 85 & 81 & 81 & 85 & 85 \\
\hline 18 & 199.5 & 112.74 & 84 & 74 & 84 & 83 & 83 & 84 & 85 \\
\hline 19 & 189 & 106.82 & 78 & 57 & 78 & 71.3 & 73 & 78 & 85 \\
\hline 20 & 178.5 & 100.9 & 77 & 58 & 77 & 65.38 & 75 & 84 & 85 \\
\hline 21 & 168 & 94.98 & 76 & 73 & 76 & 59.46 & 75 & 82 & 85 \\
\hline 22 & 157.5 & 89.06 & 75 & 72 & 75 & 53.54 & 74 & 84 & 85 \\
\hline 23 & 147 & 83.14 & 74 & 73 & 74 & 71.3 & 74 & 85 & 85 \\
\hline 24 & 136.5 & 77.22 & 86 & 70 & 86 & 65.38 & 82 & 81 & 85 \\
\hline 25 & 126 & 71.3 & 83 & 70 & 83 & 59.46 & 85 & 83 & 85 \\
\hline 26 & 115.5 & 65.38 & 85 & 61 & 85 & 53.54 & 81 & 85 & 85 \\
\hline 27 & 105 & 59.46 & 83 & 60 & 83 & 75 & 75 & 83 & 85 \\
\hline & & & & & & & & & \\
\hline
\end{tabular}

\begin{tabular}{|r|r|r|r|r|r|r|r|r|r|}
\hline 28 & 94.5 & 53.54 & 79 & 57 & 79 & 74.6 & 84 & 82.1 & 85 \\
\hline 29 & 84 & 47.62 & 81 & 58 & 81 & 73 & 83 & 81 & 85 \\
\hline 30 & 73.5 & 41.7 & 80 & 74 & 74 & 78 & 78 & 84 & 85 \\
\hline 31 & 63 & 35.78 & 76 & 74 & 72 & 72 & 88 & 78 & 85 \\
\hline 32 & 52.5 & 29.86 & 76 & 77 & 76 & 57 & 86 & 76 & 85 \\
\hline 33 & 42 & 23.94 & 75 & 76 & 87 & 58 & 87 & 76.5 & 85 \\
\hline 34 & 31.5 & 18.02 & 73 & 74 & 85 & 74 & 84 & 82.5 & 85 \\
\hline 35 & 21 & 12.1 & 72 & 57.9 & 85 & 74 & 78 & 85.3 & 85 \\
\hline 36 & 0 & 0 & 73 & 60.8 & 85 & 77 & 78 & 76 & 85 \\
\hline
\end{tabular}

\section{Pembahasan}

Berdasarkan hasil pengukuran tingkat kebisingan pada tiap titik, kemudian diolah menggunakan software Golden Surfer 14 untuk menghasilkan peta kontur kebisingan yang ditunjukkan seperti pada Gambar berikut:

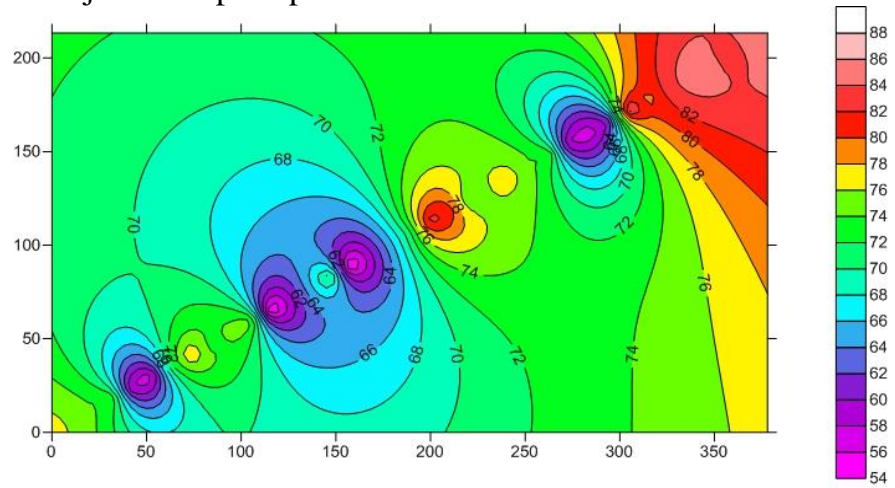

Gambar 2 Grafik Pengujian Kebisingan Di Malam Hari Ketika Hari Libur

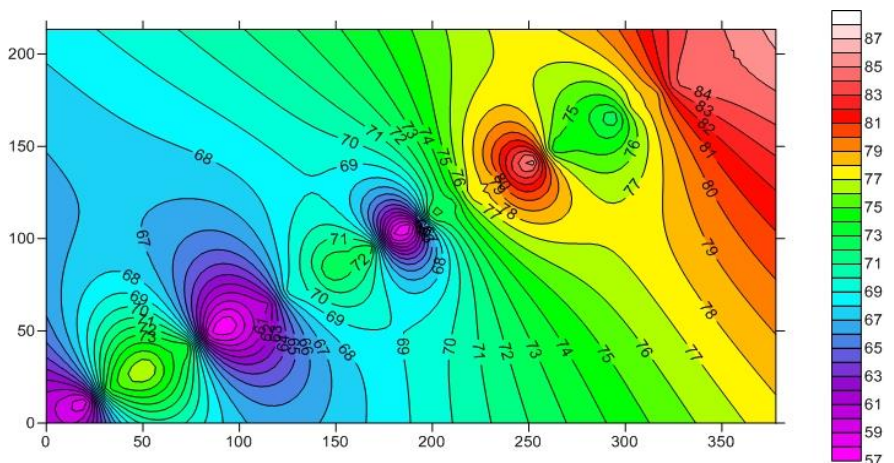

Gambar 3. Grafik Pengujiankebisingan di Malam Hari Ketika Hari Biasa

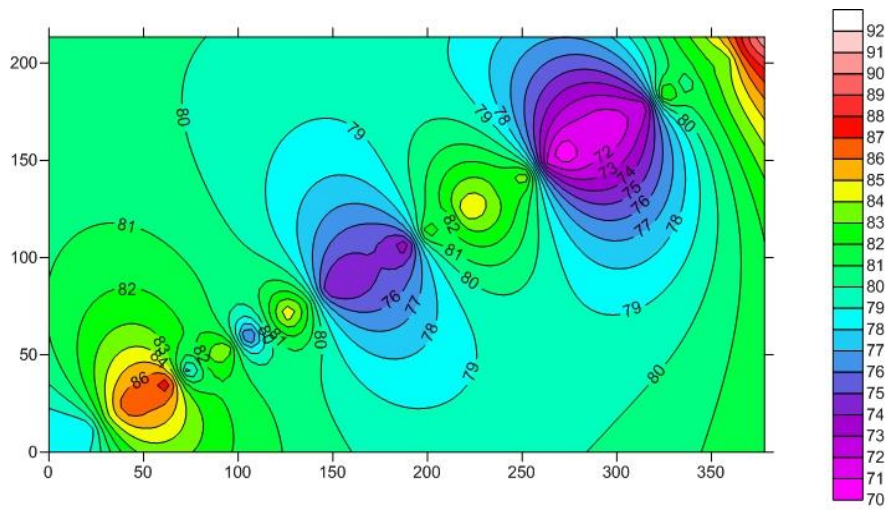

Gambar 4. Grafik Pengujian Kebisingan Malam Hari Menjelang Lebaran

Berdasarkan peta kontur kebisingan di atas, pada pengukuran yang dilakukan pada malam hari yaitu antara pukul 22.00-06.00 Wib maka dapat disimpulkan bahwa pada waktu malam hari (libur) besarnya intensitas kebisingan berkisar antara 54-88 dB, pada waktu malam hari (hari biasa) intensitasnya sebesar $57-87 \mathrm{~dB}$, sedangkan pada malam hari (menjelang lebaran) nilai intensitas meningkat antara 70-92dB. Hal ini dikarenakan adanya pengaruh kebisingan baik dari dalam maupun luar area kampus universitas semarang terutama bising yang diakibatkan kendaraan roda dua maupun kendaraan roda empat.sama halnya pengukuran yang dilakukan pada pukul 06.00-22.00 Wib besarnya intensitas kebisingan bervariasi, hal ini dapat dilihat pada grafik peta kontur dibawah ini:

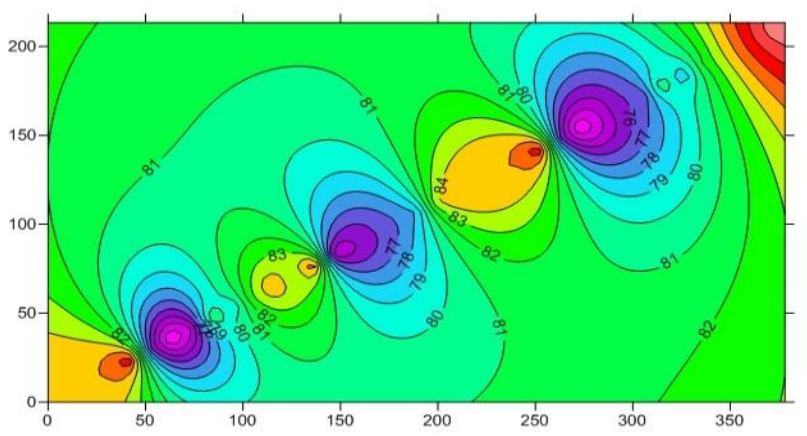

Gambar 5. Grafik Pengujian Kebisingan Di Pagi Hari Ketika Libur 


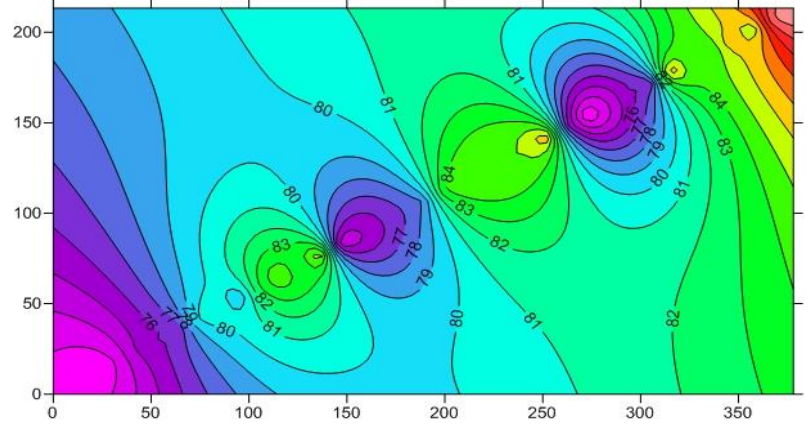

Gambar 6. Grafik Pengujian Kebisingan di Pagi Hari Hari Biasa

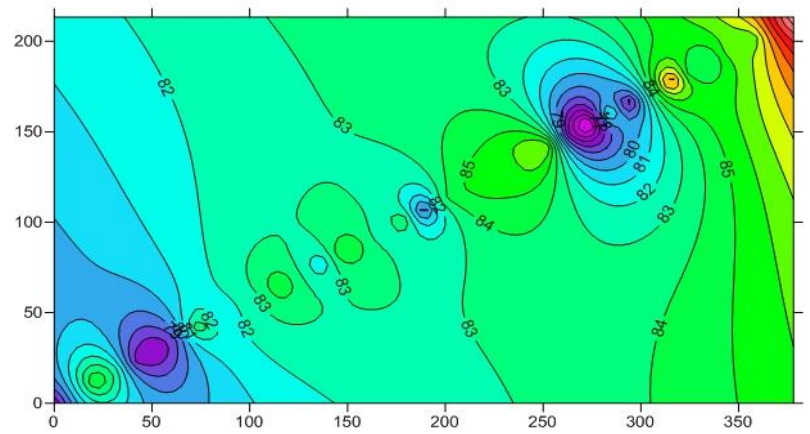

Gambar 7. Grafik Pengujian Kebisingan Pagi Hari Menjelang Lebaran

Berdasarkan grafik kontur diatas, hal ini tidak berbeda dengan pengukuran yang dilakukan pada malam hari. Pada pengambilan data pada siang hari justru mengalami peningkatan yang signifikan yang dapat ditunjukkan pada Gambar 4.6 diatas bahwa intensitas meningkat seiring dengan banyaknya jumlah kendaraan yang melewati lingkungan Universitas Semarang menjelang lebaran Idul Fitri 2018.

Dari keseluruhan, hasil pengukuran menunjukkan bahwa nilai intensitas kebisingan masih berada diatas $55 \mathrm{~dB}$, tentunya dalam hal ini kebisingan yang ada cukup mengganggu aktivitas proses belajar mengajar dilingkungan Universitas Semarang. Kondisi ini sangat tidak sesuai dengan ketentuan yang telah ditetapkan Menteri Negara Lingkungan Hidup, No.48 Tahun 1996.

Berdasarkan hasil pengujian kebisingan di lingkungan kampus Universitas Semarang, maka evaluasi kebisingan yang terjadi pada lingkungan kampus Universitas Semarang yaitu dengan melakukan identifikasi sumber kebisingan. Sumber kebisingan dapat berasal dari dalam maupun dari luar kampus. Sumber kebisingan yang berasal dari dalam lingkungan kampus pada umumnya dapat ditekan dengan melakukan teguran secara langsung, seperti gaduh karena antar mahasiswa atau alat-alat yang menimbulkan bising di dalam ruang kuliah dapat diberi tindakan langsung. Sumber kebisingan yang ditimbulkan oleh sumber dari luar ruang kuliah seperti suara mesin diesel, kendaraan bermotor, klakson kendaraan yang lewat atau yang lainnya, memerlukan berbagai tindakan untuk mengatasinya.

Sumber Kebisingan dari Luar lingkungan kampus
Sumber kebisingan yang sering terjadi selain dari aktivitas di dalam kampus adalah kebisingan yang berasal dari aktivitas di luar ruang kuliah. Universitas Semarang terletak di tepi jalan raya Soekarno-Hatta dan berbatasan dengan jalan tol secara langsung. Adapun beberapa sumber kebisingan yang sering terjadi antara lain:

1. Suara kendaraan di jalan Tol, sumber kebisingan ini bersifat terputus-putus, sering disebut juga intermittent noise, yaitu bising yang berlangsung secar tidak terusmenerus, melainkan ada periode relatif tenang. Kebisingan ini relatif tidak dapat dikendalikan, karena sudah menjadi resiko yang harus diterima sehubungan lokasi kampus di pinggir jalan Tol Kaligawe- Gayamsari.

2. Suara gaduh pembicaraan mahasiswa di luar ruang kuliah, sumber kebisingan ini bersifat terputus-putus: sering disebut juga intermittent noise, yaitu bising yang berlangsung secar tidak terus-menerus, melainkan ada periode relatif tenang. Kebisingan ini relatif dapat dikendalikan dengan memberikan teguran kepada mahasiswa yang berada di luar ruang kuliah untuk berbicara secara pelan atau dapat juga dengan memberikan teguran agar pindah tempat duduknya.

3. Suara dari genset/ diesel dan suara pekerja pemotong keramik di sekitar area gedung A, sumber kebisingan ini bersifat kontinyu berjenis Norrow Spectrum yaitu bising yang relatif tetap, akan tetapi hanya mempunyai frekuensi tertentu saja, sehingga sangat mengganggu kegiatan perkuliahan.

\section{Simpulan}

\section{KESIMPULAN}

Berdasarkan analisis dan pembahasan, maka dapat diambil kesimpulan sebagai berikut :

1. Tingkat kebisingan di lingkungan kampus Universitas Semarang belum sesuai dengan standar baku yang telah ditetapkan yaitu masih lebih besar dari (40 - 50 dBA) sesuai dengan KepMenLH No.48 Tahun 1996.

2. Aturan dan kebijakan dapat dilakukan di lingkungan Universitas Semarang untuk mengendalikan tingkat kebisingan di area gedung perkuliahan, sehingga meningkatkan kenyamanan perkuliahan.

\section{Saran}

Berdasarkan uraian di atas, maka dapat diberikan beberapa saran sesuai dengan penelitian yang telah dilakukan adalah manajemen universitas harus segera merumuskan sistem osilasi suara yang dapat diterapkan dilingkungan kampus universitas Semarang yang dapat meningkatkan kenyamanan perkuliahan di universitas Semarang.

\section{DAFTAR PUSTAKA}

Djalante, S. 2010. Analisis Tingkat Kebisingan Di Jalan Raya Yang Menggunakan Alat Pemberi Isyarat Lalu 
Lintas (APIL) (Studi Kasus: Simpang Ade Swalayan). Jurnal SMARTek.. November 2010.

Feidihal. 2007. Tingkat Kebisingan Dan Pengaruhnya Terhadap Mahasiswa di Bengkel Teknik Mesin Politeknik Negeri Padang. Jurnal Teknik Mesin. Volume 4, No. 1, Juli 2007: ISSN 1829-8958.

Mandala Adi, 2012. Belajar Surfer dan Peta Kontur. Surabaya.Graha Ilmu.

Menteri Lingkungan Hidup. 1996. Tentang: Baku Kebisingan. Surat Keputusan Menteri Lingkungan Hidup Nomor: Kep-48/MENLH/1996/25 November 1996. Jakarta.

Rahmat Kusnadi. 2013. [online] http://rahmatkusnadi6.blogspot.com/2010/07/petakontur. di akses 5 Januari 2018 pada pukul 22.03 WIB.

Sasongko,D.P, Hardiyanto A. 2000. Kebisingan Lingkungan. Universitas Diponegoro. Semarang. 